\title{
Exploring the theoretical link between cultural and emotional intelligence: A system analysis for human resource management
}

\author{
P. Jonck and E. Swanepoelb* \\ aDeputy-Director: Research and Innovation, The National School of Government, 70 Meintjies Street, Sunnyside, Pretoria \\ ${ }^{b}$ Faculty of Education: Office of the Dean, University of the Free State, Herlin 2, David Botha, Heuwelsig, Bloemfontein, 9301 \\ *To whom all correspondence should be addressed \\ swanepoeleh@ufs.ac.za
}

\begin{abstract}
In light of increasing globalisation and a changing workforce, the ability to bridge cultural fissures separating diverse groups will be increasingly critical to sustained work place well-being, especially with relation to global competitiveness and economic growth. This article explores the link between cultural and emotional intelligence in an effort to investigate the possibility of measuring, developing, and effectively managing individual responses to cultural influences that give rise to significant tension within the organisational context. Since South Africa's heterogeneous workforce is characterised by culturally diverse group interaction, the conceptualisation of a cross-cultural facet of intelligence with emotionalmanagement as reciprocal component has practical implications towards optimal intercultural organisational harmony, effective globalised interaction and overall group-dynamics.
\end{abstract}

\section{Introduction}

The function of human resource management within organisations has been altered dramatically due to a paradigm shift which has occurred ever since the emergence of a strategic element in its domain (Siddique, 2007: 294). The normative human resource management function used to include the provision, training, utilisation and maintenance of sufficient quantity of competent personnel with impeccable work ethics (Veeran, 2011: 1086). The new economic paradigm, which is governed by innovation and quality consciousness, has broadened the field to include the importance of intangible assets such as brand recognition and knowledge management. This shift led to the expansion of human resource management from an administrative function to active participation in strategic management (Siddique, 2007: 294). The philosophy of management indicates that human resource management seeks to integrate all organisational functions to focus on meeting customer needs and organisational objectives, thereby increasing organisational competitiveness (Du Plessis \& Huntley, 2009). Against this background, Sub-Saharan Africa is increasingly drawn into the competitive international market through forces of globalisation (Van der Westhuizen, 2011: 46).

The Global Competitiveness Report of 2011-2012 indicated that South Africa ranked overall $50^{\text {th }}$ out of 142 economies. Twelve indicators were utilised to determine the position of each country including institutional environment (legal and administrative framework), infrastructure, macro-economic environment, health and primary education, higher education and training, goods market efficiency, labour market efficiency, financial market development, technological readiness, market size, business sophistication and finally innovation (Schwab, Sala-i-Martin \& Greenhill, 2011: 19). The before mentioned report concluded that the lack of labour market efficiency inhibits the economic growth and global competitiveness of South Africa. Efficiency and flexibility of a country's labour market are crucial to ensure that employees are allocated to their most efficient usage in the economy, while providing employees with incentives to ensure that they offer their best efforts in their respective occupations (Schwab et al., 2011). Jonker (2009: 157) noted that human resource management is the corporate function that constantly underachieves. South Africa subsequently ranked $95^{\text {th }}$ in labour market efficiency due to unyielding industrial relation practices, a lack of flexibility in wage determination and significant tension in employee-employer interaction, to such a degree that South Africa ranked $5^{\text {th }}$ last out of 142 countries according to the Global Competiveness Report of 2011/2012 (Schwab et al., 2011: 19).

Globalisation has significant ramifications for human resource management. As such, human resource managers should not only understand global imperatives but also have the knowledge and competencies to effectively govern diverse human capital stock (Du Plessis \& Huntley, 2009: 413). The current integrated framework focuses on how cognitive ability and emotional-management play a reciprocate role in the global market. Emotionalmanagement, also referred to as emotional intelligence, can be seen as the ability to recognise the denotation related to specific emotions, assimilate emotions in thought, understand and reason with emotion and regulate emotion in self and others (Adeoye \& Torubelli, 2011:215). Wu (2011:23) refers to emotional intelligence as the impetus behind problem solving, team effectiveness and leadership in diverse work settings. These characteristics are considered as being adaptive traits which are correlated to more than intellectual ability. A growing body of research underscores the importance of emotional intelligence for human resource management (Cha, Cichy \& Kim, 2009; Reilly \& Karounos, 
2009; Yousuf \& Ahmad, 2007). The rational for the growing importance of the concept 'emotional intelligence' is based on the value added benefits thereof. Emotional intelligence is a mechanism that fosters positive stimulation of employee's innate potential, which is equivalent to approximation of the organisation's vision to personal values of staff members (Lazovic, 2012: 798).

Globalisation furthermore led to the addition of a cultural component within the dynamics of organisations. Many organisations are multicultural with products being conceived and designed in one country, produced in various other countries and marketed globally. The result is numerous dyadic relationships where the cultures of stakeholders differ (Triandis, 2006: 20). Within the South African context, organisations are implementing employment equity and affirmative action to redress previous imbalances, creating a diverse workforce (Jackson, Van de Vijver \& Ali, 2012: 1). The increasing challenges of cultural diversity and a global economy have generated growing interest in interculturality (Parent \& Varnhagen, 2011: 146) as well as multiculturalism (Jackson et al., 2012: 1). Interculturality differs from multiculturalism in the sense that multiculturalism is a descriptive term for cultural diversity as a salient characteristic of contemporary societies (Louw \& Jackson, 2008: 3), whereas interculturality seeks to bring-about a coherent theoretical framework. Multiculturalism is used as an ideology intended for coming to grips with cultural diversity encompassing the quality and positive evaluation of heterogeneous groups within a society (Jackson et al., 2012: 2). Meer and Modood (2011: 3) contrast interculturality and multiculturalism, stating that the former centres around interaction, is less group membership orientated and more yielding of synthesis while encompassing a better sense of cohesion. While multiculturalism focuses on diversity, interculturality focuses on cohesion.

Various studies have been done to investigate diversity from divergent theoretical perspectives including diversity complexity cognition (Kamp \& Engelbrecht, 2011: 38). Diversity complexity cognition refers to the ability to comprehend diversity mainly by reflecting upon the degree to which an individual's social identity are differentiated and integrated in the cognitive representation of their group membership (Brewer \& Peirce, 2005: 425). These perspectives focus mainly on group membership, while cultural intelligence is based on inherent individual characteristics (Van den Bergh, 2008: 31). Whereas group membership cannot be modified, individual characteristics can be fostered.

South Africa has probably been at the forefront of articulating the challenges associated with cultural diversity (Louw \& Jackson, 2008: 3). Conceptualising a cross-cultural facet of intelligence has enormous implications for explaining and predicting the increasing prevalent cross-cultural interactions that transpire in business settings due to globalisation (Thomas, 2006: 78). This article consequently seeks to explore the link between cultural and emotional intelligence in an effort to investigate the possibility of measuring, developing and subsequently effectively managing individual responses to cultural differences that give rise to significant tension in inter organisational relations which is within the South African context largely characterised by diversity. A systems analysis will also be done to indicate how cultural intelligence with emotional intelligence as reciprocal component can be utilised within the organisational system.

\section{Conceptualisation of the study}

\section{Cultural intelligence}

In order to explore and define cultural intelligence and core competencies related thereto it is paramount to determine what culture is. Culture is a broad and complex term that includes an individual's personal attitudes, values and beliefs, but also governs group interaction at various societal levels and is based on shared experiences that are particular to a specific group (Van den Bergh, 2008: 8). The values, attitudes and behaviour that are inherent to a particular culture (Martin, 2005: 2) provide group members with common ground and differentiate them from other groups. Culture shapes individual's cognitive processing, behaviour and affect, it provides guidelines for social and moral conduct which are manifested in unique behaviour, mannerisms, language and artefacts (Van den Bergh, 2008: 8-9).

Intelligence subsumes various definitions, but is widely recognised as the interactional ability of the individual to effectively and purposefully act and reflect within the environment, adjusting overtly and covertly within this interactional exchange (Ramesar, Koortzen \& Oosthuizen, 2009: 40). As formally connected to cognitive ability (Higgins, Peterson, Pihl \& Lee, 2007: 298), the factors rooted within the concept of intelligence include the cognitive processes related to memory, problem solving, visual identification, verbal responses and spatial capabilities (Bühner, Kröner \& Ziegler, 2008).

Against this background, cultural intelligence can be seen as the capability to effectively comprehend and adapt to a myriad of cultural context as an additional and essential skill set (Van Dyne, Ang \& Livermore, 2010: 131). Thus, the traits and skills of individuals who adjust rapidly, with minimal stress when interacting extensively in cultures other than the ones wherein they were socialised (Brislin, Worthley \& MacNab, 2006). Cultural intelligence encapsulates the capability to adapt, but ultimately to shape the context of cross-cultural interaction (Thomas, 2006: 80) and reflects upon diversity from an individual perspective and not from the perspective of group membership or society.

Cultural intelligence requires being open to understanding a culture, gaining information about the said culture from ongoing interaction, gradually adjusting cognitive processes to be sympathetic to the culture, and lastly changing operant behaviour to be more skilled and appropriate when interacting with group members form that culture (Van den Bergh, 2008: 29). Triandis (2006: 20) alluded that the most important aspect of cultural intelligence is to suspend judgment until enough information becomes available. 
Brislin et al. (2006) elaborate further by indicating that a critical skill of cultural intelligence is confusion acceptance, which includes delaying judgment until additional informational becomes available in conjunction with tolerating the uncomfortable state of confusion. Cultural intelligence consequently mitigates tension which might arise through the increased interaction between opposing cultural backgrounds.

Cultural intelligence consists of three interrelated components that combine to produce the ability to interact effectively across diverse cultures namely knowledge, mindfulness, and behavioural aptitude (Thomas, 2006: 81). Knowledge refers to knowing what culture is, how it varies and how it may influence behaviour. Mindfulness represents a heightened awareness of and enhanced attention to reality (Brown \& Ryan, 2003: 822). Mindfulness or awareness is a fundamental aspect of consciousness and is the continuous monitoring of one's emotions and the external environment. Behavioural aptitude embodies the ability to generate appropriate behaviour in new cultural settings based on knowledge and mindfulness (Thomas, 2006: 87). Similarly Van Dyne et al. (2010: 132) make note of the four-factor model of cultural intelligence by referring to the capabilities rooted within the concept.

The four factors of cultural intelligence are motivational, cognitive, meta-cognitive and behavioural factors. In synergy, the aforementioned components of cultural intelligence capture an individuals' knowledge about another culture, their behavioural repertoire to function effectively across cultures as well as the motivation to expand innate knowledge base about different cultures (Reichard, Dollwet \& Louw-Potgieter, 2014: 154). The motivational component subsumes efficacy and confidence, persistence, value congruence and affect for the new culture (Van den Berg, 2008:30). Hence, the motivational factor refers to the incentive to gain cross-cultural competence (Van Dyne et al., 2010: 134). The cognitive factor includes thinking, learning and strategising more specifically careful observance of host culture and related practices in order to understand the rationale behind it. Thus the cognitive factor includes the knowledge dimension similar to that mentioned by Thomas (2006: 81). The meta-cognitive aspect refers to suspended judgment indicated by Triandis (2006: 20) and includes the ability to access and/or generate affect when facilitating decision making as well as taking into consideration different cultural contexts. This dimension reflects the individual's ability to select applicable cultural knowledge depending on the context while rejecting immediate judgment based on salient stereotypical cues (Ang et al., 2007: 6). The behavioural dimension refers to the ability to act appropriately in a range of cross-cultural settings (Van Dyne et al., 2010: 137). In essence, the ability to act on cultural nuances which include social mimicry and adjusting of behavioural repertoire (Van den Berg, 2008: 30). A summary of the components of cultural intelligence is provided in Table 1 (Van den Bergh, 2008: 31).
Table 1: Summary of the components of cultural intelligence

\begin{tabular}{|c|c|c|}
\hline \multicolumn{2}{|r|}{ Component } & Description \\
\hline 1. & $\begin{array}{l}\text { Knowledge (Earley \& } \\
\text { Ang, 2003) } \\
\text { Meta-cognition (Ang } \\
\text { et al., 2007: 6) }\end{array}$ & $\begin{array}{l}\text { Knowledge of the fundamental } \\
\text { principles of a culture, flexibility } \\
\text { and capability to adapt own } \\
\text { views to adjust to a new situation. }\end{array}$ \\
\hline 2. & $\begin{array}{l}\text { Mindfulness (Thomas, } \\
\text { 2006: 84) } \\
\text { Motivation (Van Dyne } \\
\text { et al., 2010: 135) }\end{array}$ & $\begin{array}{l}\text { Observation and interpretation of } \\
\text { situation. } \\
\text { Willingness to persevere despite } \\
\text { the possibility of failure. }\end{array}$ \\
\hline 3. & $\begin{array}{l}\text { Behaviour (Van Dyne } \\
\text { et al., 2010: 137) }\end{array}$ & $\begin{array}{l}\text { The ability to understand and } \\
\text { execute the required actions } \\
\text { (such as language, greetings and } \\
\text { social conduct) with a reasonable } \\
\text { level of proficiency }\end{array}$ \\
\hline
\end{tabular}

Cultural intelligence facilitates the individual to comprehend cross-cultural interaction, make sense and strategise culturally diverse experiences, and the ability to adapt overt and communicative responses (both verbally and nonverbally) when interacting across a range of cultures (Van Dyne et al., 2010: 133-134).

\section{Emotional intelligence}

Emotional intelligence can be understood to include the ability to perceive, appraise and express emotion, to access and/or generate affect when it facilitates cognitive processing, to comprehend emotions and emotional knowledge, and to regulate emotions in order to promote emotional and intellectual growth (Salami, 2008: 78). Emotional intelligence represents an individual-difference variable that moderates stimulus-behaviour linkage (Jordan, Ashkanasy \& Hartel, 2002: 21).

Mayer, Salovey and Caruso (2004: 198) demarcate emotional intelligence into two distinct components: an affective and cognitive component. The affective component refers to the emotions experienced during social interaction, whereas the cognitive component refers to the ability to reason with or about an object or situation while comparing and contrasting different ideas. Table 2 provides a brief overview of the fourbranch model of emotional intelligence (Rossouw, 2008: 60). 
Table 2: Overview of the four-branch model of emotional intelligence

\begin{tabular}{|c|c|}
\hline $\begin{array}{l}\text { Perceiving } \\
\text { emotions: }\end{array}$ & $\begin{array}{l}\text { The ability to perceive emotions in oneself and } \\
\text { others, as well as in objects, art, stories, music } \\
\text { and other stimuli. }\end{array}$ \\
\hline $\begin{array}{l}\text { Facilitating } \\
\text { thought: }\end{array}$ & $\begin{array}{l}\text { The ability to generate, use, and feel emotions as } \\
\text { necessary to communicate feelings, or utilise } \\
\text { them in other cognitive processes. }\end{array}$ \\
\hline $\begin{array}{l}\text { Understand } \\
\text { ing } \\
\text { emotions: }\end{array}$ & $\begin{array}{l}\text { The ability to understand emotional information, } \\
\text { how emotions combine and progress through } \\
\text { relationship transitions and to appreciate such } \\
\text { emotional meanings. }\end{array}$ \\
\hline $\begin{array}{l}\text { Managing } \\
\text { emotions: }\end{array}$ & $\begin{array}{l}\text { The ability to be open to feelings, and to modulate } \\
\text { them in oneself and others so as to promote } \\
\text { personal understanding and growth. }\end{array}$ \\
\hline
\end{tabular}

Reflecting on the work of Goleman (2001), Richards and Barry (2010: 58) discuss four emotional intelligence skills namely self-awareness, self-management, social awareness and relationship management. Self-awareness refers to the ability to accurately perceive own emotion, while selfmanagement is indicative of the ability to manage emotional reaction. Social awareness relates to the ability to grasp the emotions of others, whereas relationship management facilitates the government of interaction and includes the adeptness at inducing desirable responses in others, aiding others to develop themselves as well as the establishment of high-quality relationships.

Rossouw (2008: 65), with reference to the work of Boyatzis and Sala (2004), refers to emotional intelligence as a competency, alternatively, a construction of competencies that manifests as overt behaviour resulting from underlying resolve also referred to as 'intent'. Understanding and regulating of one's emotions as well as cognisance of other's emotions are factors that influence intrapersonal well-being and interpersonal relations, which in turn influence employees' attitudes towards colleagues, supervisors, occupation and the organisation (Adeoye \& Torubelli, 2011: 216; De Miranda, 2011: 38). Emotional intelligence enables human resource management to assist organisations in realising their competitive advantage through improved motivation of staff, enhanced innovation, effective use of resources (human capital stock), restored trust and improved teamwork (Samad, 2009: 164). Thus emotional intelligence plays a pivotal role in the self-development of a manager (specifically human resource managers) and associated leadership qualities. Emotional intelligence result on the micro level in observed and measured increases in the productivity of employees, building positive relations and gaining emotional commitment from human capital stock. At the macro level this strengthens organisational culture, resilience and flexibility which in the long run lead to greater competitive advantage. Furthermore, empathetic communication between management and staff develop a culture of trust that increase synergy amongst employees, stimulating creativity which is essential in developing innovative responses to complex demands (Lazovic, 2012: 797).
Assessing the emotional intelligence of prospective personnel governs the intake of employees with characteristics related to psychological capital and effective group communication (Bennie \& Huang, 2011: 23). The organisational needs and the employee's emotional capabilities are furthermore aligned through the applications of emotional assessment in order to eradicate emotional dissonance and to optimise organisational success (Hur \& Moon, 2011: 1088). Research indicates that emotional intelligence is positively correlated with organisational commitment (Salami, 2008: 76), leadership effectiveness and job satisfaction (Law, Wong, Huang \& Li, 2008), resilience and adaptability (Wu, 2011: 24), as well as overall job performance (Adeoye \& Emeke, 2010).

\section{Reciprocate relationship between cultural and emotional intelligence}

Literature points to a reciprocate relationship between cultural intelligence and other types of interactive intelligence such as emotional intelligence (Brislin et al., 2006). Individuals from diverse cultures with differing norms interact and maintain different emotions. Emotional intelligence is assessed on the basis of acceptable modes of emotional expression innate to a specific culture (Ugwu, 2011: 138). The definition of emotional intelligence includes the ability to identify and express emotions, while culture influences determines outward expression (Thomas, 2006: 80). The link between cultural and emotional intelligence can be summarised as follows (see Table 3 ).

Table 3: Summary of the link between cultural and emotional intelligence

\begin{tabular}{|c|c|c|}
\hline $\begin{array}{c}\text { Cultural } \\
\text { intelligence }\end{array}$ & $\begin{array}{c}\text { Emotional } \\
\text { intelligence }\end{array}$ & Description \\
\hline Mindfulness & $\begin{array}{l}\text { Perceiving } \\
\text { emotions }\end{array}$ & $\begin{array}{l}\text { Observing and interpreting } \\
\text { of situations or emotions }\end{array}$ \\
\hline $\begin{array}{l}\text { Meta-cognitive } \\
\text { component }\end{array}$ & $\begin{array}{l}\text { Facilitating } \\
\text { thought }\end{array}$ & $\begin{array}{l}\text { Ability to generate, use and } \\
\text { feel emotions as necessary. } \\
\text { Thus flexibility and } \\
\text { capability to adjust own } \\
\text { views/emotions. }\end{array}$ \\
\hline $\begin{array}{l}\text { Behavioural } \\
\text { component }\end{array}$ & $\begin{array}{l}\text { Managing and } \\
\text { understanding } \\
\text { emotions }\end{array}$ & $\begin{array}{l}\text { Ability to understand and } \\
\text { execute the required action. } \\
\text { Thus modulate emotions in } \\
\text { self and others to promote } \\
\text { understanding and generate } \\
\text { required actions to } \\
\text { establish quality } \\
\text { relationships }\end{array}$ \\
\hline Motivation & $\begin{array}{l}\text { Intent } \\
\text { resolve }\end{array}$ & $\begin{array}{l}\text { Willingness to persevere } \\
\text { and motivation to adjust } \\
\text { accordingly. }\end{array}$ \\
\hline Knowledge & & $\begin{array}{l}\text { Knowledge of the } \\
\text { fundamental principles of a } \\
\text { culture. }\end{array}$ \\
\hline
\end{tabular}

The first comparison drawn in Table 3 reflects cultural intelligence's component of mindfulness and the branch of emotional perception on the part of emotional intelligence. Mindfulness represents awareness which is the continuous 
monitoring of one's own emotions and the external environment (Brown \& Ryan, 2003: 823). The four-branch model of emotional intelligence demarcates emotional perception as the ability to reflect with awareness on both the personal experiencing of emotions and the level of aligned interpretation of external emotional cues, leading to actions which are executed with greater certainty and sensitivity on both verbal and non-verbal levels (Rossouw, 2008: 61).

With the accurate comprehension of the cultural implications embedded within interaction, the meta-cognitive component allows for the facilitation of decision-making based on appropriate and aligned affect (Triandis, 2006: 21-23) while rejecting immediate internal cultural bias (Ang et al., 2007: 6). This links to the emotional intelligence branch of thought facilitation, which reflects the skills of generating appropriate emotions in order to facilitate interaction and decisionmaking and reason in a rational and reasonable manner (Rossouw, 2008: 61). The meta-cognitive component of cultural intelligence consequently corresponds with the affective and cognitive components of emotional intelligence, being able to observe and interpret emotional nuances and situations before adapting thought processes, thus effectively adjusting reactions for optimal interaction.

Relationship management, a skill associated with emotional intelligence (Vrba, 2007), correlates with the cultural intelligence dimension of behavioural aptitude (Thomas, 2006: 87-89; Van Dyne et al., 2010: 137), this being the ability to generate appropriate behaviour based on self- and social-awareness. Relationship management consists of team cohesion, motivation and persuasion though the accurate comprehension of other's emotions and intentions (Richards \& Barry, 2010: 58). The emotional management branch of emotional intelligence corresponds to relationship management, as defined by Rossouw (2008: 104) through reference to Caruso and Salovey (2004), as the ability to initiate adaptive behaviour in order to stabilise and harmonise the emotional context, promoting external emotional wellbeing. The behavioural component of cultural intelligence subsumes the effective execution of actions, such as language and conduct, within a range of cultural contexts (Van Dyne et al., 2010: 137), establishing greater understanding and group cohesion in turn.

Both cultural and emotional intelligence is based on motivation and intent as the final link. The motivational dimension of the four-factor model of cultural intelligence includes intrinsic and extrinsic motivation as well as selfefficacy. It is assumed that human resource managers are motivated to gain cross-cultural competencies, although employees often approach diversity training apathetically (Van Dyne et al., 2010: 135). Emotional intelligence forms the motivational core to the ability to regulate emotions in order to promote growth based on intent (Salami, 2008: 78). Emotional intelligence is thus essential to motivate both human resource managers and employees to gain crosscultural competencies and adapt their affect accordingly.

The conclusion that can be drawn is that cultural intelligence is an enabler for emotional intelligence through shaping the context and conventions within which appropriate and acceptable mood nuances and behaviours are expressed. Emotional intelligence is a component of cultural intelligence and enables the motivational dimensions towards the acquisition of cross-cultural competencies in turn, as well as management of appropriate expression of emotions within interpersonal group dynamics. The cognitive dimension of cultural intelligence which covers knowledge of cultural systems, norms and values (Van Dyne, 2010: 135-136) is the only discrepancy between emotional and cultural intelligence.

\section{A system analysis for human resource managers: theoretical application}

The theoretical application of the link between cultural and emotional intelligence within the organisational context can be illustrated as follows.

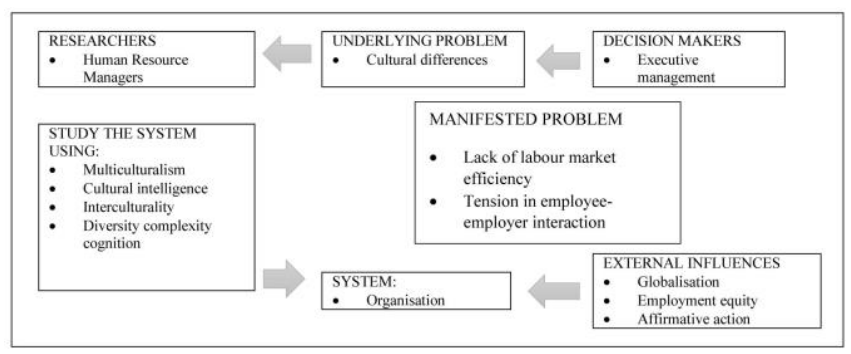

Figure 1: Organisational systems analysis (adapted from Levien, 2013)

The organisation represents the system in which certain organisational problems manifest in this instance lack of labour market efficiency and significant tension in employeeemployer interactions. The external influences that are the impetus for these problems represent globalisation, employment equity and affirmative action. The decision makers that are influenced by these manifestations due to the external dynamics are executive management. In order to solve these manifestations the researcher, in this instance a human resource manager, is instructed to investigate the underlying problem for these manifestations which is cultural differences. The human resource manager can use various analytical tools to investigate the cultural differences for example multiculturalism, interculturality, diversity complexity cognition as well as cultural intelligence. The appropriateness of these analytical tools differs. Multiculturalism, interculturality and diversity complexity cognition focus for the most part on group membership and knowledge of cultural differences. Cultural intelligence on the other hand focus on individual characteristics that can be fostered and developed to increase the individual's ability to interact with cultural diverse individuals.

The link between cultural and emotional intelligence is critical since emotional intelligence is linked to an array of prerequisites for organisational effectiveness and success (Adeoye \& Emeke, 2010; Hur \& Moon, 2011; Samad, 2009; Yousuf \& Ahmad, 2007) with a large body of research on emotional intelligence programs. These can be adjusted to 
include knowledge of cultural systems, norms and values in order to measure, develop and effectively manage individuals' responses to cultural differences as well as to develop emotional intelligence. Combining cultural and emotional intelligence will significantly increase organisational effectiveness and increase cost and time effectiveness.

\section{Conclusion}

In order for South Africa to increase its level of global competitiveness, attention should be given to the efficiency and flexibility of the country's labour market with specific reference to inter organisational interaction. The corporate function that is foremost responsible for inter organisational interaction is human resource management. Two constructs that play a reciprocal role in the before mentioned interaction are emotional and cultural intelligence. While both emotional and cultural intelligence is applicable on employees and employers, the central group mediation role of human resource management revolves to a large extent around cultural intelligence to govern diverse human capital stock.

The conceptualisation of a cultural facet of intelligence has enormous implications for explaining and predicting the increase of prevalent diverse interactions that currently transpire in business settings. This article explored the link between emotional and cultural intelligence in an effort to investigate the possibility of measuring, developing and effectively managing individual responses to cultural differences that give rise to significant tension within the organisational context. The link between cultural and emotional intelligence can lead to developmental programs that address both these critical aspects within a single program to increase cost and time effectiveness. Consequently, this article aims to establish a theoretical link for more comprehensive research into cultural intelligence for human resource management. Further research should focus on assessing the status and nature of cultural intelligence in corporate South Africa. Since South Africa has been at the forefront of articulating challenges associated with cultural diversity, lessons learned can be transferred to other countries and is of significant international value.

\section{References}

Adeoye, H. \& Emeke, E.A. 2010. 'Emotional intelligence and selfefficacy as determinants of academic achievement in English Language', IFE Psychologia, 18(1): 252-269.

Adeoye, H. \& Torubelli, V. 2011. 'Emotional intelligence and human relationship management as predictors of organisational commitment', IFE Psychologia, 19(2): 212-226.

Ang, S., Van Dyne, L., Koh, C., YeeNg, K., Templer, K.J., Tay, C. \& Chandrasekar, N.A. 2007. 'Cultural intelligence: its measurement and effects on cultural judgment and decision making, cultural adaption and task performance', Management and Organisation Review, 3(3): 335-371.
Bennie, C. \& Huang, T. 2010. 'Gender differences in stress management, emotional management and emotional expression within the workplace', New Voices in Psychology, 6(2): 23-44.

Boyatzis, R.E. \& Sala, F. 2004. Assessing emotional intelligence competencies. In Glenn, G. (Ed.). The Measurement of Emotional Intelligence. Hauppauge, NY: Novas Science Publishers.

Brewer, M.B. \& Pierce, K.P. 2005. 'Social identity complexity and out-group tolerance', Social Psychology Bulletin, 31(3): 1-10.

Brewster, C., Carey, L., Grobler, P., Holland, P. \& Wärnich, S. 2008. Contemporary issues in Human Resource Management. 3rd Edition. Cape Town: Oxford University Press.

Brislin, R., Worthley, R. \& MacNab, B. 2006. 'Cultural intelligence: Understanding behaviours that serve people's goals', Group and organisation Management, 31(1): 40-55.

Brown, K.W. \& Ryan, R.M. 2003. 'The benefits of being present: mindfulness and its role in psychological well-being', Journal of Personality and Social Psychology, 84(4): 822-848.

Bühner, M., Kröner, S. \& Ziegler, M. 2008. 'Working memory, visual-spatial-intelligence and their relationship to problemsolving', Intelligence, 36, 672-680.

Caruso, D.R. \& Salovey, P. 2004. The emotionally intelligent manager. San Francisco: Jossey-Bass.

Cha, J., Cichy, R.F. \& Kim, S.H. 2009. 'The contribution of emotional intelligence to social skills and stress management skills among automated foodservice industry executives', Journal of Human Resources in Hospitality and Tourism, 8(1): 15-31.

De Miranda, L.C.S. 2011. The relationship between emotional intelligence and leadership effectiveness with an emphasis on corporate culture in a consumer goods organisation. Unpublished Master's Thesis, University of Pretoria, Pretoria.

Du Plessis, A.J. \& Huntley, K. 2009. 'Challenges in a globalised context for international human resource managers in South African organisations', International Review of Business Research Paper, 5(1): 413-427.

Early, P.C. \& Ang, S. 2003. Cultural intelligence: individual interactions across cultures. Stanford, CA: Stanford University Press.

Goleman, D. 2001. An EI-based theory of performance. In Cherniss, C. and Goleman, D. (Eds.). The Emotionally Intelligent Workplace. San Francisco: Jossey-Bass.

Higgins, D., Peterson, J.B., Pihl, R.O. \& Lee, A.G.M. 2007. 'Prefrontal cognitive ability, intelligence, big five personality, and the prediction of advanced academic and workplace performance', Journal of Personality and Social Psychology, 93(2): 298-319.

Jackson, L.T.B., Van de Vijver, F.J.R. \& Ali, S. 2012. 'Positive acculturation and well-being in a mine in the North-West province', South African Journal of Industrial Psychology, 38(1): 1-11.

Jonker, C.S. 2009. 'The effect of an emotional intelligence development programme on accountants', South African Journal of Human Resource Management, 7(1): 1-9. 
Jordan, P.J., Ashkanasy, N.M. \& Hartel, C.E.J. 2002. 'Emotional intelligence as a moderator of emotional and behavioural reactions to job insecurity', Academy of Management Review, 27(3): 361-372.

Kamp, J.M. \& Engelbrecht, A.S. 2011. 'The influence of emotional intelligence on diversity complexity cognition and the attitude towards diversity', South African Journal of Business Management, 42(3): 37-48.

Law, K.S., Wong, C., Huang, G. \& Li, X. 2008. 'The effect of emotional intelligence on job performance and life satisfaction for research and development scientists in China', Asia Pacific Journal of Management, 25(1): 51-69.

Lazovic, S. 2012. The role and importance of emotional intelligence in knowledge management. Paper presented at the 'Management, Knowledge and Learning International Conference', 20-22 June, Celje, Slovenia.

Levien, R. 2013. The craft of systems analysis. Paper presented at "the Southern Africa Young Scientist Summer Program", 14 January, University of the Free State, Bloemfontein.

Louw, L. \& Jackson, T. 2008. 'Managing culture and change in South African organisations: The way forward for Sub Saharan Africa?', Africanus, 38(1): 29-42.

Martin, J. 2005. Organisational Culture. In Nicholson, N., Audia, P. and Pillutla, M. (Eds.). The Blackwell Encyclopedic Dictionary of Organisational Behaviour. 2nd Edition. Oxford, England: Basil Blackwell Ltd.

Mayer, J.D., Salovey, P. \& Caruso, D.R. 2004. 'Emotional intelligence: Theory, findings and implications', Psychological Inquiry, 15(3): 197-215.

Meer, N. \& Modood, T. 2011. 'How does interculturalism contrast with multiculturalism?', Journal of Intercultural Studies, 33(2): 175-196.

Moon, T.W. \& Hur, W.M. 2011. 'Emotional intelligence, emotional exhaustion, and job performance', Social Behaviour and Personality, 39(8): 1087-1096.

Parent, R. \& Varnhagen, S. 2011. 'Designing a semiotic-based approach to intercultural training', Sign System Studies, 39(1): 145182.

Ramesar, S., Koortzen, P. \& Oosthuizen, R.M. 2009. 'The relationship between emotional intelligence and stress management', South African Journal of Industrial Psychology, 35(1): 39-48.

Reichard, R.T., Dollwet, M. \& Louw-Potgieter, J. 2014. 'Development of cross-cultural psychological capital and its relationship with cultural intelligence and ethnocentrism', Journal of Leadership and Organisational Studies, 21(2): 150-164.

Reilly, A.H. \& Karounos, T.J. 2009. 'Exploring the link between emotional intelligence and cross-cultural leadership effectiveness', Journal of International Business and Cultural Studies, 1-13.

Richards, Y. \& Barry, M.L. 2010. 'The relevance of emotional intelligence in project management for the aviation industry', Journal of Contemporary Management, 7: 56-70.
Rossouw, A. 2008. The relationship between health and emotional intelligence. Unpublished Master's Thesis, University of South Africa, Pretoria.

Salami, S.O. 2008. 'Demographic and psychological factors predicting organisational commitment among industrial workers', Anthropologist, 10(1): 31-38.

Samad, S. 2009. 'The influence of emotional intelligence on effective leadership among managers in Malaysian business organisations', The Business Review, 13(1): 164-170.

Schwab, K., Sala-i-Martin, X. \& Greenhill, R. 2011. The Global Competitiveness Report 2011-2012. Geneva: World Economic Forum.

Siddique, Z. 2007. 'The influence of strategic human resource management on emotional competencies', International Review of Business Research Papers, 3(4): 294-305.

Thomas, D.C. 2006. 'Domain and development of cultural intelligence: The importance of mindfulness', Group and Organisation Management, 31(1): 78-99.

Triandis, H.C. 2006. 'Cultural intelligence in organisations', Group and Organisation Management, 31(1): 20-26.

Ugwu, L.I. 2011. 'Emotional and general intelligence: Characteristics, meeting points and missing links', Asian Social Sciences, 7(7): 137-140.

Van den Berg, R. 2008. Cultural Intelligence: a comparison between managers in South Africa and the Netherlands. Unpublished Master's Thesis, University of Pretoria, Pretoria.

Van der Westhuizen, J. 2011. 'Globalisation and human resource management: An integrated framework for the African public service', Politeia, 30(2): 46-65.

Van Dyne, L., Ang, S. \& Livermore, D. 2010. Cultural intelligence: A pathway for leading in a rapidly globalising world. In Hannum, K., McFeeters, B.B. \& Booysen, L. (Eds.). Leading across differences. San Francisco: Pfeiffer.

Veeran, P. 2011. 'The impact of globalisation on human resource management policies and procedures in the South African public service', Journal of Public Administration, 46(3): 1086-1099.

Vrba, M. 2007. 'Emotional intelligence skills and leadership behaviour in a sample of South African first-line managers', Management Dynamics, 16(2): 26-35.

Wu, Y. 2011. 'Job stress and job performance among employees in the Taiwanese finance sector: The role of emotional intelligence', Social Behaviour and Personality, 39(1): 21-32.

Yousuf, S. \& Ahmad, I. 2007. 'Emotional intelligence as predictor of managerial effectiveness', Journal of Behavioural Sciences, 17: 21-35. 
